\title{
Ammonia as an Alternative for Fuel Internal Combustion Engines
}

\author{
Kanchuka Dissanayake \\ Sam Houston State University, USA
}

\begin{abstract}
Internal combustion engines have been used to power automobiles for more than a century using gasoline and diesel as the primary sources of energy. With the introduction of stricter fuel economy regulations such as Corporate Average Fuel Economy (CAFE) standards in the light of environmental pollution, global warming and fuel scarcity new alternative fuels have been researched. Ammonia is such an alternative fuel used for decades and have picked up the momentum recent years. In this paper three recent attempts to use ammonia as a fuel for internal combustion engine have been reviewed.
\end{abstract}

\section{Introduction}

Internal combustion engines provide outstanding drivability and durability, with more than 250 million highway transportation vehicles in the United States relying on them. Along with gasoline or diesel, they can also utilize renewable or alternative fuels (e.g., natural gas, propane, biodiesel, ethanol or ammonia). They can also be combined with hybrid electric powertrains to increase the fuel economy or plug-in hybrid electric systems to extend the range of these vehicles [1].

While new drilling technologiesand oil reserves are taking the pressure off gasoline prices and peak production issues, demand for alternative fuel vehicles continues to grow. Environmental concernsand government regulations have made finding substitutes for the conventional gasoline-powered internal combustion engine a priority for both manufacturers and consumers. The federal government is demanding an average of 54.5 miles per gallon by 2025 - a challenging target for traditional technologies. California is requiring increasing numbers of zero-emission or plug-in hybrid cars [1].

An alternative fuel vehicle is a vehicle that runs on a fuel other than traditional petroleum fuels (gasoline or diesel fuel); and also refers to any technology of powering an engine that does not involve solely petroleum (e.g. electric car, hybrid electric vehicles, solar powered). Because of some combination of factors, such as environmental concerns, high oil prices and the potential for peak oil, development of cleaner alternative fuels and advanced power systems for vehicles has become a high priority for many governments and vehicle manufacturers around the world [2].

Ammonia is an alternative fuel used for decades in internal combustion engines and have picked up the momentum again recent years. Ammonia is a substantial hydrogen carrier which can be used as a storage method of hydrogen energy. It has the potential to reduce the emission pollutants, carbon monoxide and unburnt hydro carbons when combusted completely. Anhydrous ammonia is a compound containing one atom of nitrogen and three atoms of hydrogen $\left(\mathrm{NH}_{3}\right)$. Ammonia contains about $17 \%$ by weight of hydrogen, which is much better than all other non-carbon based hydrogen storage methods. Industrially, anhydrous ammonia is usually supplied as liquid at about $150 \mathrm{psi}$ at ambient temperature. Thus, ammonia has a huge potential to be used as an alternative for petroleum fuels [3].

In this paper three recent attempts to use ammonia as a fuel for internal combustion engine have been reviewed. These systems includes: Ammonia-gasoline fuel blends, ammonia-gasoline dual fuel system and ammonia-metal amine complexes. These research were led by three independent research groups. Together they provide a comprehensive understanding of the feasibility of using ammonia in internal combustion engines.

\section{Ammonia-Gasoline Fuel Blends}

This research is led by a Texas Tech University (Lubbock, TX) research team. Team has used anhydrous ammonia blended with gasolineand other emulsifiers. Ammonia, when blended with hydro carbon fuels, can be used as a composite fuel to power existing internal combustion (IC) engines. Such blends, similar to ethanol and gasoline fuel blends can be used to commercialize ammonia as an alternative fuel which does not require end user equipment (vehicular) modifications or infrastructure changes [3].

Ammonia is a polarized molecule and gasoline is a non-polarized molecule with a long carbon chain. This reduces the solubility of ammonia in gasoline. Emulsifiers or cross linkers with non-polarized and polarized parts in the molecule, can be used to enhance the solubility under this situation. Ethanoland methanol have both polarized (OH-) and non-polarized $\left(-\mathrm{C}_{2} \mathrm{H}_{5} /-\mathrm{CH}_{3}\right)$ molecular structure. Thus it can be used as an emulsifier to enhance the solubility of ammonia in hydrocarbon fuels. Solubility of ammonia in ethyl alcohol 
was estimated to be $85 \mathrm{~g} / \mathrm{l}$ in atmospheric pressure and $293.15 \mathrm{~K}$. It was experimentally proven that the solubility of ammonia in the liquid phase of pure ethanol is $120 \mathrm{~g} / \mathrm{l}$ at $45.2 \mathrm{psi}$ and $208.75 \mathrm{~K}$. Due to the higher polarity and shorter carbon chain methanol has higher emulsifying capabilities. Literature shows the solubility of ammonia in pure methanol is $258.1 \mathrm{~g} / \mathrm{l}$ at $44.7 \mathrm{psi}$ and $313.75 \mathrm{~K}$ [3, 4, 5]. According to the Texas tech University research team these fuels are named as E30A17.35 and M30A30.00 respectively. The performance of ammonia rich fuels are compared with the baseline fuel in the figures 1 and $2[6,7,8]$.

Images indicates Break Mean Effective Pressure (BMEP) in an engine cylinder of fuel variants under a dynamometer test. These dynamometer tests are carried out under same environmental conditions. Ammonia rich fuels have preformed as equally as the baseline fuels considered in the research. Despite the merits and demerits of ethanoland methanol

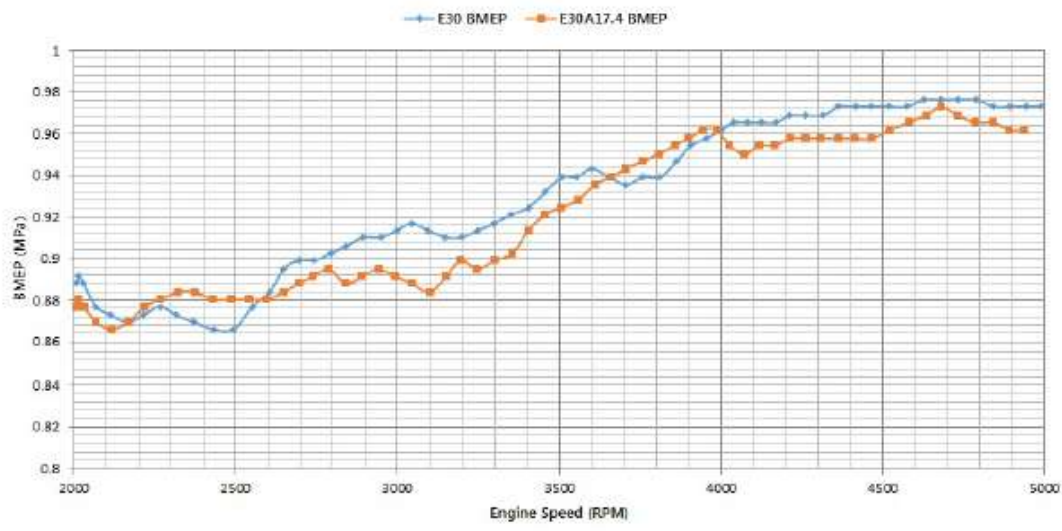

Fig. 1. E30 and E30A17.35 dyno test results

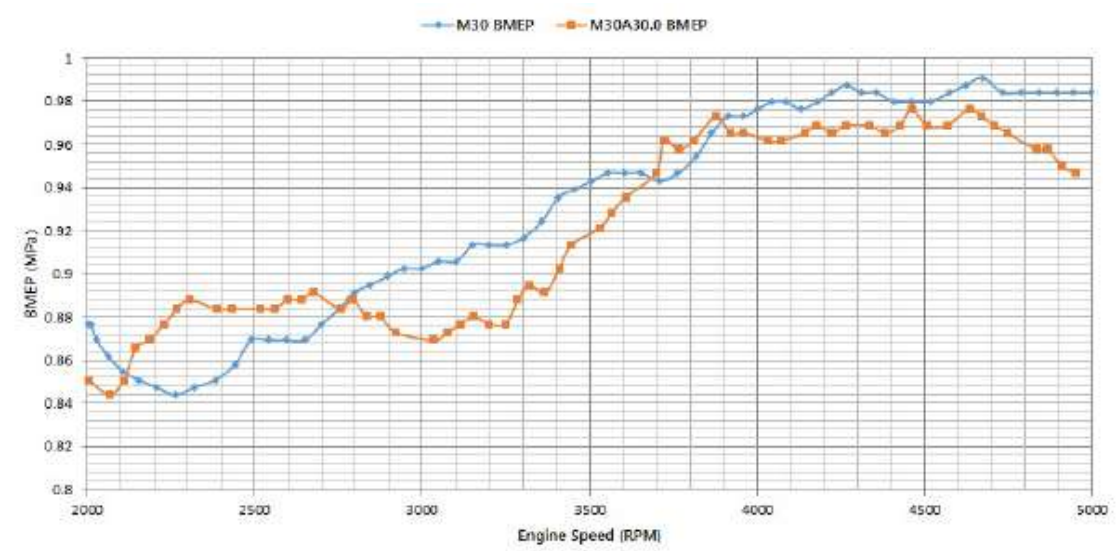

Fig. 2. M30 and M30A30.00 dyno test results

they are used in the automotive industry as a transportation fuel. Therefore both ethanol and methanol can be used as economically feasible emulsifiers for ammonia-gasoline fuel blends.

The octane rating of ammonia is relatively higher than that of gasoline. Thus ammonia and gasoline blends have a higher octane rating than pure gasoline. Higher specific heat capacity of ammonia can help to reduce the combustion temperature inside the combustion chamber which results in lower cooling power. These factors can be considered as the reasons for increase in power and torque levels and decrease in exhaust temperature particularly at higher engine speeds. Engine knocking issues can be expected to be eliminated with the increased octane number. Thus better compression ratios can be utilized for ammonia rich fuels. Literature study shows that better performance characteristics are achieved when ammonia rich fuels are bench-marked against baseline fuel especially at higher engine speeds $[3,4,5,6,8]$.

Emissions characteristics and fuel consumption characteristics of the ammonia blends remains to be studied further to drawa complete conclusion about the fuel blends. However, according to the literature ordinary three-way catalytic converters and exhaust gas oxygen sensors can be used to clean up emissions from ammonia-gasoline dual fueled spark ignition engines to the required emission levels. 


\section{Ammonia-Gasoline Dual Fuel Systems}

In 2007 a research team at the University of Michigan led by S.M. Grannell successfully used a test vehicle for a cross country trip from Ann Arbor to San Francisco, California, USA, using a mixture of ammoniaand gasoline as a fuel where gasoline itself was used as the combustion promoter [9]. The fuels were stored on board in two different storage containers and ammonia was mixed with vaporized gasoline (vaporized by the gasoline injector) just before the intake plenum. Figure 3 shows a picture of the actual fuel delivery system.

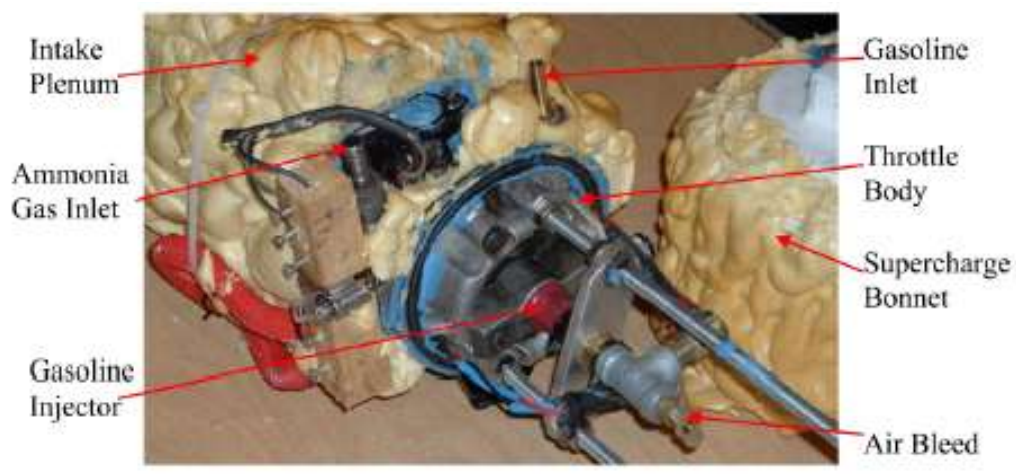

Fig. 3. Fuel delivery system proposed by S.M. Grannell et al.

Two fuel containers are required to be on board the vehicle which consumes passenger and/or cargo space but this method does not inherit some of the other disadvantages as mentioned in the discussion section. A careful redesign or modification of, the vehicle to accommodate this requirement is necessary. S.M. Grannelland his research team from the University of Michigan employed the proposed fuel system in a 1995 4-cylinder Chevrolet S-10 pickup and used the test vehicle for a cross country trip from Ann Arbor to San Francisco, USA [9]. The engine was run on pure gasoline at idle and $70 \%$ of ammonia and $30 \%$ of gasoline mixture (based on the lower heating value of energy) at normally aspirated, wide open throttle conditions. $50 \%$ of the average energy consumption was supplied from ammonia during the $3740 \mathrm{~km}$ journey. The total fuel consumption was recorded as 183 liters of gasoline and 295 kilograms of ammonia. At an average fuel consumption rate of 13.84 liters per $100 \mathrm{~km}$ (17 mpg of fuel economy of 1995 Chevrolet S-10) the test vehicle would have used 517 liters of gasoline if run with pure gasoline.

\section{Ammonia-Metal Amine Complexes}

C.S. Morch suggested metal ammine complexes as an on-board ammonia storage method [10]. Proposed configuration to use metal ammine complex $\mathrm{Mg}\left(\mathrm{NH}_{3}\right)_{6} \mathrm{Cl}_{2}$ is shown in figure $4 . \mathrm{MgCl}_{2}$ is used as the hydrogen carrier and is proposed as a safe transport method for the ammonia. $\mathrm{Mg}\left(\mathrm{NH}_{3}\right)_{6} \mathrm{Cl}_{2}$ is then heated using exhaust gas to desorb ammonia from the complex. Further ammonia is then decomposed in to nitrogen and hydrogen in order to provide hydrogen as a combustion promoter. Used metal ammine complex $\left(\mathrm{MgCl}_{2}\right.$ if fully desorbed) is then recharged (absorb new ammonia) in a central location.

The research objective was focused on measuring the performance of the engine with the dual fuel system and ammonia and hydrogen were supplied from two different containers. Performance of the desorption and decomposition system is analyzed and it is shown that the maximum possible energy that can be used for this system is $40 \%$ of the total energy requirement at a compression ratio (CR) of 7 and a speed of 1200 RPM. This value further reduces to approximately $10 \%$ at CR of 10 and speed of 1200 RPM. However, it is mentioned that decomposition of ammonia requires high temperatures $\left(550^{\circ} \mathrm{C}\right.$ to $\left.600{ }^{\circ} \mathrm{C}\right)$ and a substantial amount of heat which cannot be supplied solely from the exhaust gas. In the absence of the exhaust heat during the transient operation conditions of the vehicle (start up), an external heat source is required to run this system. Energy density per unit mass in $\mathrm{Mg}\left(\mathrm{NH}_{3}\right)_{6} \mathrm{Cl}_{2}$ is relatively low when compared to gasoline, hydrogen and ammonia. This issue is further augmented if the $\mathrm{Mg}\left(\mathrm{NH}_{3}\right)_{6} \mathrm{Cl}_{2}$ is not completely desorbed, highlighting the few practical issues in actual implementation of this system. 


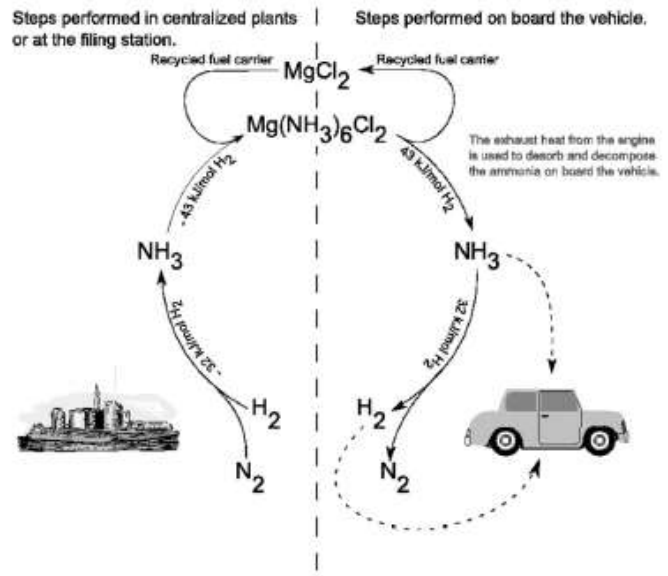

Fig. 4. On board ammonia storage as $\mathrm{Mg}\left(\mathrm{NH}_{3}\right)_{6} \mathrm{Cl}_{2}[10]$

C. S Morch et al. used a CFR engine of $612.5 \mathrm{~cm}^{3}$ in SI setup to study the effect of hydrogen-ammonia fuel mixture on efficiency and power [10]. Several compression ratios (6.23 to 13.58) were studied in the research to explain the effect of $\mathrm{CR}$ on the power and efficiency. The power and efficiency was measured at (Maximum Brake Torque) MBT spark timing and it was revealed that the mean effective pressure (MEP) increase with the increasing CR.

\section{Discussion}

Each method considered in the review has its own pros and cons. Ammonia-gasoline fuel blend system needs minimal equipment modification. This system needs a high pressured single fuel tank to store the fuel blend and leak proof re-filling system. Dual fuel storage systems inject ammonia in to the combustion chamber at the point of injection or on-board catalytic reforming of hydrogen from ammonia. Two major drawbacks of this system is the new injector system and the necessity to have second on board fuel storage tank for ammonia. The third system uses metal amine complexes to store ammonia on board and then uses heating and decomposing mechanism to release ammonia from the metal amine complex and break part of released ammonia in to hydrogen and nitrogen. There are several drawback of this system when compared to other two. It needs two additional system to provide fuel and also the initial energy needed for these systems has to be obtained from a secondary energy source. When all these three system are considered, it is evident ammoniagasoline fuel blend system requires least amount of new mechanisms/equipment to be utilized. Therefore it can be concluded that ammonia-gasoline fuel blends could be used to commercialize ammonia as an alternative energy source in a short period of time.

\section{References}

[1]. O. of Energy and R. Energy, "Internal combustion engine basics," November 2013.

[2]. Wikipedia, "Alternative fuel vehicle," November 2016.

[3]. S. O. Haputhanthri, T. T. Maxwell, J. Fleming, and C. Austin, "Ammonia and gasoline fuel blends for spark ignited internal combustion engines," Journal of Energy Resources Technology, vol. 137, no. 6, p. 062201, 2015.

[4]. S. O. Haputhanthri, "Ammonia gasoline fuel blends: Feasibility study of commercially available emulsifiers and effects on stability and engine performance," tech. rep., SAE Technical Paper, 2014.

[5]. S. O. Haputhanthri, T. T. Maxwell, J. Fleming, and C. Austin, "Ammonia gasolineethanol/ methanol tertiary fuel blends as an alternate automotive fuel," in ASME 2014 International Mechanical Engineering Congress and Exposition, pp. V06AT07A071V06AT07A071, American Society of Mechanical Engineers, 2014.

[6]. S. O. Haputhanthri, T. T. Maxwell, J. Fleming, and C. Austin, "Ammonia and gasoline fuel blends for internal combustion engines," in ASME 2014 8th International Conference on Energy Sustainability collocated with the ASME 2014 12th International Conference on Fuel Cell Science, Engineering and Technology, pp. V002T04A012- V002T04A012, American Society of Mechanical Engineers, 2014.

[7]. C. Austin, "Internal combustion engine performance with ammonia fuel blends," PhD thesis, Texas Tech University, 2013.

[8]. S. O. Haputhanthri, C. Austin, T. Maxwell, and J. Fleming, "Ammonia and gasoline composite liquid fuel blends emulsified with ethanol and methanol for direct displacement in internal combustion engines," IOSR J. Mech. Civil Eng, vol. 11, no. 2, pp. 11-18, 2014.

[9]. S. M. Grannell, D. N. Assanis, S. V. Bohac, and D. E. Gillespie, "The Fuel Mix Limits and Efficiency of a Stoichiometric, Ammonia, and Gasoline Dual Fueled Spark Ignition Engine,” Journal of Engineering for Gas Turbines and Power, vol. 130, no. 4, p. $042802,2008$.

[10]. C. S. Mørch, A. Bjerre, M. P. Gøttrup, S. C. Sorenson, and J. Schramm, “Ammonia/ hydrogen mixtures in an SI-engine: Engine performance and analysis of a proposed fuel system," Fuel, vol. 90, no. 2, pp. 854-864, 2011. 